Journal Wetenskap Health

\title{
Pesticide Use Related to Pesticide Poisoning Factors and the Impact of Pesticide Exposure on Health
}

\author{
Angie Adel $^{1}$, Barlenti Akefiwad ${ }^{1}$ \\ ${ }^{1}$ Environmental Health and Safety department, The American University in Cairo, Egypt
}

\begin{abstract}
Pesticides are chemicals used to kill pests, both insects, fungi and weeds. Pesticides have been widely used for the purpose of eradicating pests and plant diseases in agriculture. The classification of the severity of pesticide exposure seen from the activities carried out is divided into four categories ranging from the lowest to the highest. A person with increasing age causes the metabolism function to decrease, so the average level of cholinestrase in the blood will be lower, making it easier for pesticide poisoning. Many studies have shown that there is a close relationship between the lengths of pesticide exposure
\end{abstract}

\section{Introduction}

Pesticides are substances to kill or control pests (Edwards, 1993). The Food and Agriculture Organization (FAO) defines that a pesticide is any substance that is expected to prevent, destroy or control any pests including vectors against humans or diseases in animals, and unwanted plants or animals that cause damage during the production process, storage or marketing. food, agricultural commodities, wood and wood production, or animal food ingredients

The benefits of pesticides encourage farmers to use pesticides in controlling plant pests (Cooper \& Dobson 2007). Pesticides can not only kill the target organism but can kill the nontarget, such as humans. This is because there are still many farmers who use pesticides without paying attention to ecological and health aspects, even though there have been many regulations regarding the use of pesticides issued by the government

If exposure to pesticides is associated with environmental preservation, the use of pesticides needs to be watched out because it can endanger the environment and the health of humans and other living things. Many types of pesticides, resulting in many victims of pesticide poisoning are reported either intentionally or unintentionally. Pesticide poisoning has been reported by accident among officers who spray plant pests on agricultural land (Van 1998). The impact on the environment due to the use of pesticides is related to the effectiveness of pesticides. Pesticides that have toxic properties can affect the entire taxonomy of biota, including living things. Some pesticides are resistant to environmental degradation, so that it can affect natural ecosystems in the long term Farmers who are in frequent contact with pesticides are very vulnerable to the harmful effects of these pesticides. Pesticide poisoning that occurs can be divided into three, namely acute, subacute, and chronic. One of the factors in the occurrence of pesticide poisoning in spraying farmers is due to the way of storing, mixing, and washing sprayers that are not in accordance with the rules of the pesticide guidelines. According to the results of research from Prijanto (2009), it means that there is a significant relationship between storage method $(\mathrm{p}=0.011)$, mixing place $(\mathrm{p}=0.030)$, and post-spraying pesticide handling (0.001) with the incidence of organophosphate pesticide poisoning in the farmer's wife. Meanwhile, according to research by Mokoagow, Joseph \& Patras (2013), the method of processing or handling pesticides has no relationship with blood cholinesterase levels in vegetable farmers with $\mathrm{p}$ value $=0.509$. 


\section{Definition and Use of Pesticides}

Pesticides are chemicals used to kill pests, both insects, fungi and weeds (Batish 2008). Pesticides have been widely used for the purpose of eradicating pests and plant diseases in agriculture. Pesticides are also used in households to combat mosquitoes, cockroaches and various other pests. On the other hand, this pesticide actually causes a lot of poisoning in people.

Pesticides are chemical substances used to kill or control various pests. Pesticides come from the English language, namely pesticides means pests and cida means killing (Bonney \& Quansah, 2020). The definition of pests for farmers is very broad, namely: mites, nuisance plants, plant diseases caused by fungi, bacteria, and viruses, nematodes (worms that damage roots), snails, rats, and other animals deemed harmful (LeClerg, 1979). Based on Ministerial Decree concerning Requirements and Procedures for Registration of Pesticides, what is meant by pesticides are all chemical substances and other materials as well as microorganisms and viruses used for; Eradicate or prevent pests and diseases that damage crops, plant parts or agricultural products; Eradicating the grass; Kills leaves and prevents unwanted growth; Regulate or stimulate the growth of plants or plant parts excluding fertilizers; Eradicate or prevent external pests on domestic animals and livestock; Eradicate or prevent water pests; Eradicating or preventing animals and microorganisms in households, buildings in transportation means; Eradicate or prevent animals that can cause disease in humans or animals that need to be protected by use on plants, soil, or water.

The definition of pesticides is very broad and includes products used in the field of crop management (agriculture, plantations, forestry) (Furlan \& Kreutzweiser, 2015). Animal husbandry, animal health, fisheries, storage of agricultural products, preservation of forest products: public health (including disease vector control), buildings (especially for termite control), household pesticides, fumigation, and industrial pesticides. In particular, pesticides used in crop management are called crop protection products (crop protection agents) or agricultural pesticides. This mention is intended to distinguish the type of pesticide from pesticides used in other fields

\section{Pesticide Active Ingredients}

The active ingredients of pesticides were found to reach 53 types, for insecticides dominated by pyrethroids (41.38\%), Organophosphates (13.79\%), and Carbamates $(10.34 \%)$. About $73.91 \%$ fungicide is mancozeb which is included in the dithiocarbamat group. According to WHO, this active ingredient is included in group $\mathrm{U}$ (does not cause acute harm in normal doses), group III (quite dangerous). Group II (dangerous), to Group Ib (very dangerous). As much as $12 \%$ of all insecticides found were triazophos (organophosphates), metamidophos (organophosphates), carbofuran (carbamates) and beta siflutrin (ptieroid).

\section{Pesticide Formulations}

\section{Solid Formulation}

Wettable Powder (WP), is a flour dosage form (particle size of a few microns) with a relatively high content of active ingredients (50-80\%), if mixed with water will form a suspension Wraight \& Carruthers (1999) WP application by spraying. Soluble Powder (SP), is a flour formulation which when mixed with water will form a homogeneous solution. Used by spraying. Granules, is a ready-to-use preparation with a low concentration of active ingredients (2\%). The grain size varies from 0.7 to $1 \mathrm{~mm}$. application by sprinkling. Water Dispersible Granule (WG or WDG), in the form of WDG granules, must be diluted first with water and applied by spraying it. Soluble Granule (SG) is similar to WDG which must also be diluted 
with water before being used by spraying it. The difference is, if it is mixed with SG water it will form a perfect solution. Blowing Flour, is a ready-to-use preparation in the form of flour (particle size 10-3 microns) with a low concentration of active ingredients $(2 \%)$ used by blowing (dusting).

\section{Liquid Formulation}

Emulsifiable Concentrate or Emulsible Concentrate (EC), is a concentrated liquid preparation with a high content of active ingredients (Xiao 2020). If mixed with water, it will form an emulsion (liquid particles floating in other liquid media). Together with the WP formulation, the EC formulation is the classic formulation most widely used today.

Water Soluble Concentrate (WCS) is a formulation similar to EC, when mixed with water it does not form an emulsion, but will form a homogeneous solution (Elsabee \& Abdou 2013). This formulation is used by spraying. Aquaeous Selution (AS), is a concentration that can be dissolved with water. Generally, pesticides that have high solubility in water, this formulation is used by spraying. Soluble Liqiud (SL), is a liquid concentration, if mixed with liquid concentrated water it will form a solution. This pesticide is used by spraying.

Ultra Low Volume (ULV), for spraying with ultra-low volumes, namely the spray volume between 1-5 liters / hectare. ULV formulations are generally oil based because for ultra-low volume spraying, very fine spray droplets are used.

\section{Pesticide Exposure Classification}

The classification of the severity of pesticide exposure seen from the activities carried out is divided into four categories ranging from the lowest to the highest, there is no exposure at all; indirect exposure, namely people who only plant; residential exposures that is, people who use pesticides for their own household gardens; agricultural exposure, namely people who take part in mixing pesticides, repair targets who spray pesticides or people who apply pesticides directly to the plant.

\section{Pesticide Poisoning Factors}

\section{Factors outside the body}

The time of spraying needs to be considered when spraying pesticides, in general it is recommended that a good time to spray pesticides is in the morning and in the afternoon. This is related to the environmental temperature which can cause more sweat, especially during the day. High environmental temperature will facilitate the absorption of organophosphate pesticides into the body through the skin and/or digestion (Kamrin, 1997).

Spraying during the day with high temperatures will cause metabolism in the body to increase and absorption of pesticides into the body to be greater. The bad environment temperature for pesticide spraying farmers is if it is higher than human body which is 37OC. If the environmental temperature is high, the body temperature will also increase, causing vosolidation, namely the blood vessels expand to be close to the skin (external environment) which allows heat to be released out, more blood on the skin to make it easier for blood heat to be freed out through the process of irradiation and sweating, water The sweat that is infiltrated by the sweat glands has a certain heat so that it can absorb high heat and is released into the surrounding environment when the sweat water evaporates. Suh that exceeds the stipulated condition makes farmers sweat easily so that the pores open a lot and pesticides will easily enter through the skin.

Proper spraying must be in the direction of the wind so that the spray mist is not blown into the direction of the sprayer and spraying should be carried out at wind speeds below 750 
meters per minute. Farmers spraying against the wind direction will have a greater risk of pesticide poisoning when compared to farmers who spray crops downwind.

All types of pesticides are poison, the greater the dose, the easier it is to poison farmers using pesticides. The dosage of pesticides has a direct effect on the danger of pesticide poisoning which is determined by the length of exposure. The recommended dose is $0.5-1.5 \mathrm{~kg}$ / ha for field spraying, especially the organophosphate group.

The longer the spraying per day, the higher the exposure intensity that occurs. Farmers should not be exposed to pesticides more than 5 hours per day or 30 hours in one week. The longer the working time is used and the more frequent the spraying is, the greater the exposure to pesticides which results in decreased cholinesterase activity. The longer the farmers spray, the more pesticides will stick in the body, causing blood cholinesterase to be bound by pesticides. Spraying that is carried out with high frequency without the use of personal protective equipment (PPE) will affect the cholinesterase of farmers even though the duration of spraying will be carried out $<5$ hours a day.

\section{Factors in the body}

A person with increasing age causes the metabolism function to decrease, so the average level of cholinestrase in the blood will be lower, making it easier for pesticide poisoning. Age is also related to immunity in overcoming the level of toxicity of a substance, the older a person is, the less effective the immune system will be

Female farmers tended to have higher cholinesterase levels on average than men. Farmers with poor nutritional status tend to be at greater risk of poisoning when working with organophosphate and carbamate pesticides. Cholinesterase enzyme is formed from protein and in a state of poor nutrition, the protein in the body is limited, so that the formation of the enzyme calinestrase is disrupted.

Generally people who suffer from hepatitis, cirrhosis, metastatic carcinoma of the liver, jaundice, productive drugs, myocardial infarction and dermatomyositis have low levels of the enzyme cholinesterase. Diisoproyfluorophospate which is used as a treatment for myasthenia gravis, paralytic ileus.

Nicotine has an effect similar to acetylcholinesterase on muscle fibers so that it is able to invade cholinesterase at the synapse causing it to not hydrolyze achetylcholine which is released in the final plate. As a result, the amount of achetylcholine increases along with the onset of implants so that it stimulates muscle fibers and causes hemalian.

\section{Impact of Pesticide Exposure}

Several studies have shown a relationship between a history of exposure to pesticides with thyroid dysfunction, anemia, spontaneous abortion, birth defects, and low birth weight (LBW) (Wigle 2007).

\section{Thyroid Fungi}

A history of exposure to pesticides in the organochlorine class in pregnant women is a risk factor for the occurrence of cogenital hypothyroidism and cretinism.

\section{Anemia}

Anemia can occur in people with organophosphate and carbamate poisoning due to the formation of sulfhemoglobin and methemoglobin in red blood cells (Kanias \& Acker, 2010; Gulati et al., 2020). Sulfhemoglobin occurs because of the high sulfur content in pesticides, causing Sulfhemoglobin bonds. Sulfhemoglobin is a form of hemoglobin that binds to the 
sulfur atom in it. This causes the hemoglobin to be abnormal and unable to carry out its function in delivering oxygen. In addition, it can also be caused by the binding of nitrite with $\mathrm{Hb}$ to form methomoglobin which causes $\mathrm{Hb}$ to not be converted back into normal hemoglobin Erythrosives can be referred to as normochromic, hypochromic, hyperchromic. Erythrocytes are said to be normochromic, meaning they contain hemoglobin in an amount that is less than normal color variations and abnormal colors indicate cytoplasmic content. The general term for color variation is anisochromia. Hypochromia occurs due to insufficient iron reserves, resulting in decreased hemoglobin synthesis. Hypochromia is clinically associated with iron deficiency anemia. Changes in erythrocyte color also indicate the state of cell immaturity.

\section{Spontaneous Abortion}

Griebel et al., (2005) states that the risk of spontaneous abortion has been investigated in a number of groups of workers' wives. Women who work in agriculture are more likely to experience spontaneous abortion than women who are not exposed.

\section{Low Birth Weight (LBW)}

Many studies have shown that there is a close relationship between the length of pesticide exposure to the incidence of LBW pregnant women involvement in agricultural activities, the presence of pesticides in the house, the completeness of personal protective equipment, the presence of agricultural products on BBRI was found to be closely related

Efforts to implement vector control can be carried out by the Government, Local Government, and/or the private sector by health entomologists and other trained personnel, namely those who have attended vector control training from an accredited training institution. Insecticide application personnel must have competition in the fields of health entomology, vector control and have received a certificate from an accredited educational and training institution. The training material for the implementation staff is basic knowledge of vectorborne disease epidemology, entomology and infectious animals, vector surveillance, vector control and skills in handling equipment such as IRS, Fogging, ULV, etc.

\section{Conclusion}

Control of vectors and nuisance animals is an effort to reduce or reduce the population of vectors or nuisance animals with the aim of preventing or eradicating diseases transmitted or disturbing (nuisance) by these nuisance vectors and animals.

\section{References}

Batish, D. R., Singh, H. P., Kohli, R. K., \& Kaur, S. (2008). Eucalyptus essential oil as a natural pesticide. Forest ecology and management, 256(12), 2166-2174.

Bonney, F., \& Quansah, R. (2020). Association between Exposure to Organochlorine and Pyrethroid Pesticides and Neurobehavioral Outcomes among Children Under Five Years Old in Offinso North District of Ashanti Region, Ghana (Doctoral dissertation).

Cooper, J., \& Dobson, H. (2007). The benefits of pesticides to mankind and the environment. Crop Protection, 26(9), 1337-1348.

Del Prado-Lu, J. L. (2007). Pesticide exposure, risk factors and health problems among cutflower farmers: a cross sectional study. Journal of Occupational Medicine and Toxicology, 2(1), 9.

Edwards, C. A. (1993). The impact of pesticides on the environment. In The pesticide question (pp. 13-46). Springer, Boston, MA. 
Elsabee, M. Z., \& Abdou, E. S. (2013). Chitosan based edible films and coatings: A review. Materials Science and Engineering: C, 33(4), 1819-1841.

Furlan, L., \& Kreutzweiser, D. (2015). Alternatives to neonicotinoid insecticides for pest control: case studies in agriculture and forestry. Environmental Science and Pollution Research, 22(1), 135-147.

Griebel, C. P., Halvorsen, J., Golemon, T. B., \& Day, A. A. (2005). Management of spontaneous abortion. American family physician, 72(7), 1243-1250.

Kamrin, M. A. (1997). Pesticide profiles: toxicity, environmental impact, and fate. CRC press.

Kanias, T., \& Acker, J. P. (2010). Biopreservation of red blood cells-the struggle with hemoglobin oxidation. The FEBS journal, 277(2), 343-356.

LeClerg, E. L. (1979). Nature and Extent of Damages Caused by Plant Pests. Introduction to Crop Protection, 1-38.

Gulati, K., Thokchom, S. K., \& Ray, A. (2020). Impact of chemical warfare agents on the immune system. In Handbook of Toxicology of Chemical Warfare Agents (pp. 685703). Academic Press.

Van Der Hoek, W., Konradsen, F., Athukorala, K., \& Wanigadewa, T. (1998). Pesticide poisoning: a major health problem in Sri Lanka. Social science \& medicine, 46(4-5), 495-504.

Wigle, D. T., Arbuckle, T. E., Walker, M., Wade, M. G., Liu, S., \& Krewski, D. (2007). Environmental hazards: evidence for effects on child health. Journal of toxicology and environmental health, part B, 10(1-2), 3-39.

Wraight, S. P., \& Carruthers, R. I. (1999). Production, delivery, and use of mycoinsecticides for control of insect pests on field crops. In Biopesticides: use and Delivery (pp. 233269).

Xiao, Q., Chen, G., Zhang, Y., Weng, H., Cai, M., \& Xiao, A. (2020). Evaluation of a novel self-emulsifiable dodecenyl succinylated agarose in microencapsulation of docosahexaenoic acid (DHA) through spray-chilling process. International Journal of Biological Macromolecules, 163, 2314-2324. 